\title{
Incorrect sleeping position and eye rubbing in patients with unilateral or highly asymmetric keratoconus: a case-control study
}

\author{
Adrien Mazharian ${ }^{1} \cdot$ Christophe Panthier ${ }^{1,2} \cdot$ Romain Courtin $^{1,2} \cdot$ Camille Jung $^{3} \cdot$ Radhika Rampat $^{1,2} \cdot$ Alain Saad $^{1,2,4}$. \\ Damien Gatinel ${ }^{1,2}$
}

Received: 16 February 2020 / Revised: 19 May 2020 / Accepted: 25 May 2020 / Published online: 10 June 2020

(C) The Author(s) 2020

\begin{abstract}
Purpose To evaluate eye rubbing and sleeping position in patients with Unilateral or Highly Asymmetric Keratoconus (UHAKC).

Methods Case-control study of consecutive UHAKC patients diagnosed at the Rothschild Foundation. Controls were age- and sex-matched, randomly selected refractive surgery clinic patients. Patients self-administered questionnaires regarding their family history of keratoconus, eye rubbing, and sleeping habits. All the eyes underwent a comprehensive ocular examination. Logistic regression was used to analyze univariate and multivariate data to identify risk factors for keratoconus.

Results Thirty-three UHAKC patients and 64 controls were included. Univariate analyses showed that daytime eye rubbing $[\mathrm{OR}=172.78]$, in the morning [OR $=24.3]$, or in eyes with the steepest keratometry [OR $=21.7]$ were significantly different between groups. Allergy [OR $=2.94]$, red eyes in the morning [OR $=6.36]$, and sleeping on stomach/sides [OR $=14.31]$ or on the same side as the steepest keratometry [OR $=94.72]$ were also significantly different. The multivariate model also showed statistical significance for most factors including daytime eye rubbing [OR $=134.96$ ], in the morning [OR $=24.86]$, in the steepest eye $[\mathrm{OR}=27.56]$, and sleeping on stomach/sides $[\mathrm{OR}=65.02]$ or on the steepest side $[\mathrm{OR}=144.02]$. A univariate analysis in UHAKC group, comparing the worse and better eye, showed that eye rubbing [OR $=162.14]$ and sleeping position $[\mathrm{OR}=99.74]$ were significantly $(p<0.001)$ associated with the worse eye.

Conclusion Our data suggests that vigorous eye rubbing and incorrect sleeping position are associated with UHAKC. This is especially true in rubbing the most afflicted eye, and contributory sleep position, including positions placing pressure on the eye with the steepest keratometry.
\end{abstract}

Keywords Eye rubbing $\cdot$ Unilateral keratoconus $\cdot$ Asymmetric keratoconus $\cdot$ Sleeping position $\cdot$ Risk factors $\cdot$ Case-control

Electronic supplementary material The online version of this article (https://doi.org/10.1007/s00417-020-04771-z) contains supplementary material, which is available to authorized users.

\section{Damien Gatinel}

gatinel@gmail.com

1 Ophthalmology department, Fondation Ophtalmologique Adolphe de Rothschild, 25 Rue Manin, 75019 Paris, France

2 Institut Laser Vision Noémie de Rothschild, Paris, France

3 Clinical Research Center, Biological Resources Center, Centre Hospitalier Intercommunal de Créteil, Créteil, France

4 Department of Ophthalmology, American University of Beirut Medical Center, Beirut, Lebanon

\section{Introduction}

Keratoconus $(\mathrm{KC})$ is a corneal ectatic disorder that has been classically defined as a progressive, asymmetric, and often bilateral, non-inflammatory condition occurring in adolescence or early adulthood that produces a thinning and steepening of the cornea and causes irregular astigmatism, myopia, and poor visual acuity [1]. The estimated prevalence of $\mathrm{KC}$ is approximately 50 to $230 / 100,000 .{ }^{1}$ People are usually affected bilaterally although it is often asymmetric [2]. The reported prevalence of eye rubbing ranges from 66 to $73 \%$ in patients with $\mathrm{KC}$, which is concerning as approximately $15 \%$ of the worldwide population appears to be suffering from ocular allergies, even more so in industrialized countries [3]. Some studies support that $\mathrm{KC}$ is associated with parental 
consanguinity [4] or other genetic systemic disorders [5], which may render some population genetically more susceptible to the disease than others. Keratoconus could then be triggered by an environmental factor such as repeated biochemical stress on a genetically fragile cornea. However, even if there is a genetic support [6], no causative gene(s) has yet been found and most of keratoconus cases are sporadic. This multifactorial disease with underlying genetic, biomechanical, and environmental processes has remained poorly understood for more than 150 years. A high percentage of KC patients have an atopic disease or allergy, and as a consequence, they frequently rub their eyes [7]. Rabinowitz [8] and Naderan et al. [9] performed case-control studies which found that keratoconus patients rubbed their eyes more often than normal controls ( 80 and $83 \%$ vs. 58 and $52 \%$, respectively).

Eye rubbing is of great concern to eye care practitioners in symptomatic patients, such as patients with ocular allergy, and they usually question patients about the frequency of these symptoms during their routine clinical practice [10]. Repetitive mechanical trauma can cause corneal weakening, by increasing apoptosis and oxidative damage, due to cyclic shear stress on corneal microstructures [11]. McMonnies and Boneham [12] proved a significant relationship between severe eye rubbing and keratoconus on the side of hand dominance. However, there are also examples in the literature [13] of keratoconus after chronic eye rubbing by the nondominant hand. The reported frequency of unilateral KC, as a subset of $\mathrm{KC}$ patients, varies depending on the methods used for diagnosis [14]. The reported frequency of unilateral KC using computerized videokeratography techniques ranges between 0.5 and 4\% [2]. Different studies [15-19] have shown that KC patients display a higher prevalence of obstructive sleep apnea compared with the general population. Another study has shown an association between floppy eyelid syndrome and $\mathrm{KC}$ [20]; it seems to be a cause of corneal collagen crosslinking failure [21]. In our clinical practice, we have noticed that patients with unilateral keratoconus often sleep on their stomach or on their side, with a direct contact of the eye on the pillow ("pillow hugging").

To our knowledge, there is no study in the literature that evaluates the possible influence of the patient's sleep position on the development of keratoconus. Therefore, the aim of this case-control study was to assess eye rubbing and sleeping position in French patients with unilateral or highly asymmetric keratoconus (UHAKC).

\section{Methods}

\section{Inclusion and exclusion criteria}

This study included consecutive patients from the Rothschild Foundation, Paris, France, between January 2017 and April
2018. Patients with UHAKC were diagnosed by senior ophthalmologists in the team. Controls were subjects presenting to the preoperative refractive surgery clinic. All candidates for refractive surgery (controls) were myopic with or without astigmatism (Table 3 ). They were clinically and topographically evaluated and showed no signs of $\mathrm{KC}$ after examination by the ophthalmologists involved in this study. To maximize the power and comparison value of the study, the eye with the steepest keratometry was selected in control patients to be compared with the worse eye of the $\mathrm{KC}$ patients. The initial examination included measurement of best-corrected visual acuity (BCVA) as well as anterior segment, lens, vitreous, and retina evaluation with slit-lamp biomicroscopic examination. Both the Topolyzer (Oculus, Wetzlar, Germany) and Orbscan II topographers (Bausch \& Lomb, New Jersey) were used to obtain maximum, minimum, and mean keratometry values (Kmax, Kmin, and Kmean, respectively) as well as the simulated keratometry (SimK) and central corneal thickness $(\mathrm{CCT}, \mu \mathrm{m})$, so that systematic errors due to keratometry measurements using different systems were therefore unlikely. The Ocular Responsible Analyzer ( ${ }^{\circ}$ (ORA; Reichert Ophthalmic Instruments, Buffalo, NY) system was used to evaluate corneal biomechanics (corneal hysteresis $[\mathrm{CH}]$ and corneal resistance factor [CRF]). A wavefront analysis was also performed using the OPD-SCAN III (Nidek Inc., Tokyo, Japan).

In order to classify a cornea as Normal (N), KC, or UHAKC (Table 1), we used a combination of quantitative videokeratography-derived indices [22] using different systems (Topolyzer and Orbscan). Normal eyes $(\mathrm{N})$ were controls and UHAKC were cases. For the Orbscan, a Score Analyzer designed by Dr. D. Gatinel and Dr. A. Saad [23] was used. A SCORE (Score Analyzer, Orbscan) of $>4$ in both eyes was chosen to define KC eyes; a SCORE of $<1.5$ in both eyes was used to define normal eyes (controls); a SCORE of $>4$ in the affected eye and $<1.5$ in the contralateral eye was used to define UHAKC eyes. Based on the Topolyzer criteria [24-26], we used the Belin Ambrosio display final D index (BAD-D index) as this has shown better results than the surface curvature indices for detecting very mild forms of ectasia. In addition, patients in the KC group measured a BAD-D index (Topolyzer) $>5.0$ in both eyes. The $\mathrm{N}$ group consisted of patients with a BAD-D index $<$ 1.4 in both eyes. The UHAKC group measured a BAD-D index $>5.0$ in the involved eye and $<1.4$ in the contralateral eye. Regarding the OPD-SCAN III, the setting "keratoconus suspects (KCS) $>50 \%$ " was selected. In the UHAKC group, this criterion was present only in the affected eye and not in the contralateral eye. Worse eyes and better eyes were analyzed in UHAKC patients using topographic parameters such as the Kmax, Kmin, Kmean, CCT, and the inferior-superior value (I-S) in the 3-mm area. Exclusion criteria consisted of patients younger than 18 years old and older than 45 years old, patients with previous eye surgery or cross-linking, any compulsive disorders involving 
Table 1 Parameters used to define control eyes, keratoconus eyes and unilateral or highly asymmetric keratoconus (UHAKC) eyes

Non-UHAKC eyes Keratoconus eyes (KC) UHAKC eyes (UHAKC)

(N)

Orbscan II system (Bausch \& Lomb)

Score Analyzer $>4$

Score Analyzer $<1.5$

Pentacam (Oculus, Wetzlar)

Belin/Ambrosio enhanced ectasia total derivation (BAD-D) $>5$ No, in both eyes

Belin/Ambrosio enhanced ectasia total derivation (BAD_D) Yes, in both eyes $<1.4$

OPD-SCAN III (Nidek)

Keratoconus suspects $(\mathrm{KCS})>50 \%$
No, in both eyes

Yes, in both eyes

\begin{tabular}{|c|c|}
\hline $\begin{array}{l}\text { Yes, in one or both } \\
\text { eyes }\end{array}$ & Yes, in the affected eye \\
\hline No, in both eyes & Yes, in contralateral eye \\
\hline
\end{tabular}

Yes, in one or both eyes

No, in both eyes $\quad$ Yes, in contralateral eye

No, in both eyes $\quad$ Yes, in both eyes
Yes in the affected eye and not in the contralateral eye eye rubbing [27, 28] (autism, Tourette syndrome, Down syndrome), and the coexistence of an infectious or irritating ocular disorder (except allergy). The study was conducted in accordance with the tenets of the Declaration of Helsinki. Informed consent was obtained from all patients after presentation of the study protocol.

\section{Questionnaire}

We explained the goal of the research project to all patients that were invited to participate in the study. UHAKC and nonUHAKC patients were asked to complete a validated [29] selfadministered questionnaire to collect exposure information anonymously (Supplementary data). The questionnaire included age, gender, ethnicity, family history of $\mathrm{KC}$ or corneal transplantation, health status, medications, allergies, and contact lens usage. We also interviewed a witness (the spouse or a family member) during the consultation, if present, with the patient's agreement. In addition, subjects were asked to report their sleeping position (on the back, stomach, or sides), past and current ocular itching, as well as past and current eye rubbing. If "eye rubbing" was present, certain significant variables were ascertained. These included time and duration of eye rubbing, gentle or vigorous in nature, unilateral, or bilateral, and finally a demonstration was asked of the patient. At each follow-up visit, all UHAKC patients were reminded about the risk of continuing eye rubbing and the detrimental effects.

Additional informed consent was obtained from nonUHAKC patients in order to make available obscured (for anonymity) photos and/or videos of their eye rubbing and sleeping habits. This information is available at the website: https://defeatkeratoconus.com/allcases/ [30].

\section{Main outcome}

The main outcome was the presence or the absence of independent predictors of the disease in the UHAKC group versus the control group. The topographic parameters and risk factors such as eye rubbing and sleeping position were also analyzed between the worse eye and the better eye in the UHAKC group only.

\section{Statistical analysis}

A retrospective statistical analysis was performed by an independent statistician, using STATA Statistics ${ }^{\circledR}$ software. A $p$ value $<0.05$ was considered statistically significant. Cases and controls were individually only matched for age and sex. Normality of continuous data was assessed using the Anderson-Darling normality test calculator. A T test was used for continuous variables if the normality assumption was met and the Mann-Whitney test was used when the data were not normally distributed. Univariate and multivariate conditional logistic regression analyses were performed. Odds Ratios (OR) and $95 \%$ confidence intervals were calculated to determine whether any factor was significantly associated with unilateral KC. From a pilot study, a power calculation was performed, and the minimal sample size was estimated at 30 patients for UHAKC and 62 controls using the Kirkwood and Sterne formula, according to the "controls/UHAKC patients" ratio. Finally, we also performed a univariate analysis to compare worse eye and better eye in the UHAKC group.

\section{Results}

\section{Demographics and corneal characteristics}

Ninety-seven patients were included in this study: 33 cases (UHAKC) and 64 controls (normal).

Table 2 presents patient demographics in both groups. Cases and controls were matched for age and sex. The mean age was not significantly different between the UHAKC 
Table 2 Patient demographics in the UHAKC and control groups

\begin{tabular}{|c|c|c|c|}
\hline & UHAKC & Controls (N) & $p$ value \\
\hline Total of patients & 33 & 64 & \\
\hline Age (year) & & & 0.45 \\
\hline Mean & $29.18(7.38)$ & $28.05(6.33)$ & \\
\hline Range & $26-31$ & $26-29$ & \\
\hline \multicolumn{4}{|l|}{ Sex } \\
\hline Women & 7 (21.2) & $14(21.9)$ & 1 \\
\hline Men & $26(78.8)$ & $50(78.1)$ & \\
\hline BCVA & $0.66( \pm 0.22)$ & $1( \pm 0)$ & $<0.001$ \\
\hline Ethnicity (\%) & $\begin{array}{c}\text { Caucasian (52\%), Arabic (33\%), } \\
\text { African (15\%), Asian (1\%) }\end{array}$ & $\begin{array}{c}\text { Caucasian (59\%), Arabic (25\%), } \\
\text { African (13\%), Asian (3\%) }\end{array}$ & 0.37 \\
\hline
\end{tabular}

BCVA: Best Corrected Visual Acuity

group and the control group $(p=0.45), 29.18 \pm 7.38$ years (range, 26-31 years) and $28.05 \pm 6.33$ years (range, 2629 years), respectively. The mean follow-up duration was 20.3 months. In both groups, the majority of the participants were male $(78.8 \%$ in cases group versus $78.1 \%$ in controls; $p=1)$. The BCVA was significantly lower in the UHAKC group $(0.66)$ than in controls $(p<0.001)$. Most of patients were Caucasian and Arabic in the 2 groups; they were also Africans and more rarely Asians. There was no statistical difference for ethnicity, with a $p$ value of 0.37 (see Table 2).

Table 3 shows corneal parameters for cases and controls Kmax, Kmin, and Kmean; Simulated keratometry (SimK) and Cylinder (Cyl) were significantly higher in the UHAKC group as compared to the control group $(p<0.001)$. In addition, $\mathrm{CCT}$ was significantly thinner in the UHAKC group as compared to the control group, $493.73 \pm 31.07 \mu \mathrm{m}$ versus 520.52 $\pm 22.69 \mu \mathrm{m}(p<0.001)$, respectively. Corneal hysteresis $(\mathrm{CH})$ and corneal resistance factor (CRF) were significantly

Table 3 Corneal data in the UHAKC and control groups based on Orbscan values

\begin{tabular}{llll}
\hline & UHAKC eyes & Controls (N) & $p$ value \\
\hline Kmax (D) & $45.78 \pm 2.60$ & $44.22 \pm 1.33$ & $<0.001$ \\
Kmin (D) & $44.07 \pm 1.91$ & $43.03 \pm 1.23$ & $<0.001$ \\
Kmean (D) & $44.94 \pm 1.62$ & $43.13 \pm 1.03$ & $<0.001$ \\
SimK & $2.13 \pm 2.02$ & $0.88 \pm 0.67$ & $<0.001$ \\
Cyl (D) & $1.87 \pm 1.53$ & $0.86 \pm 0.59$ & $<0.001$ \\
CCT ( $\mu$ m) & $495.73 \pm 31.07$ & $520.52 \pm 22.69$ & $<0.001$ \\
CH & $8.51 \pm 0.49$ & $11.30 \pm 1.30$ & $<0.001$ \\
CRF & $8.53 \pm 1.63$ & $12.18 \pm 1.27$ & $<0.001$ \\
ISV (3 mm) & $1.66 \pm 0.21$ & $0.47 \pm 0.12$ & $<0.001$ \\
Mean Sphere & $-2.21 \pm 1.01$ & $-2.6 \pm 1.66$ & $p=0.08$ \\
Mean Astigmatism & $-1.82 \pm 0.74$ & $-0.88 \pm 0.65$ & $<0.001$ \\
\hline
\end{tabular}

$C C T$ central corneal thickness, $C H$ corneal hysteresis, $C R F$ corneal resistance factor, $I S V$ index of surface variance $(p<0.001)$ lower in the case group as compared to the control group. In contrast, the inferior-superior value (I-S) in the 3$\mathrm{mm}$ area was significantly higher in the UHAKC group versus the control group, $1.66 \pm 0.21$ versus $0.47 \pm 0.12(p<0.001)$, respectively. The mean refractive astigmatism was significantly higher in the UHAKC group versus the control group; $1.82 \pm 0.74$ versus $-0.88 \pm 0.65(p<0.001)$. The mean refractive sphere was not significantly different between groups.

\section{Univariate analysis}

Table 4 shows the results of the univariate analysis of the various factors for the UHAKC and control groups. The strongest associations were found between the UHAKC group and eye rubbing during the day $(\mathrm{OR}=172.78 ; p<0.001)$ and sleeping on the steepest side $(\mathrm{OR}=94.72 ; p<0.001)$.

The recognized risk factors such as eye rubbing in the morning $(\mathrm{OR}=24.3 ; p<0.001)$, eye rubbing in the steepest side $(\mathrm{OR}=21.7 ; p<0.001)$, the presence of allergy $(\mathrm{OR}=$ $2.94 ; p=0.02)$, red eyes in the morning $(\mathrm{OR}=6.36$; $p<0.001)$, and sleeping on stomach or sides $(\mathrm{OR}=14.31$; $p<0.001$ ) were significantly associated with the presence of UHAKC in the univariate analysis.

The association between UHAKC and the stress at work was strong but not significant $(\mathrm{OR}=3.34, p=0.06)$. Family history of $\mathrm{KC}(\mathrm{OR}=1.97 ; p=0.63)$, work at night $(\mathrm{OR}=$ $0.87 ; p=0.87)$, working in front of a computer screen $(\mathrm{OR}=0.88 ; p=0.81)$ were not found to be significantly different between UHAKC and control group. Eye rubbing with the dominant hand was not significantly associated with UHAKC $(\mathrm{OR}=1.04 ; p=0.96)$.

\section{Multivariate analysis}

Table 5 shows the multivariate analysis based on seven variables that were identified significant in the univariate analysis. The multivariate analysis confirmed the significance of five 
Table 4 Univariate analysis of risk factors for UHAKC

\begin{tabular}{|c|c|c|c|c|}
\hline Risk factor & UHAKC eyes & Controls $(\mathrm{N})$ & OR $95 \% \mathrm{CI}$ & Pearson chi-square $p$ value \\
\hline Family history of $K C$ & & & $1.97(0.12-32.51)$ & 0.63 \\
\hline Yes & $1(3.0 \%)$ & $1(1.6 \%)$ & & \\
\hline Eye rubbing during the day & & & $172.78(21.13-1413.39)$ & $<0.001^{*}$ \\
\hline Yes & $32(97.0 \%)$ & $10(15.6 \%)$ & & \\
\hline Eye rubbing in the morning & & & $24.3(7.99-73.92)$ & $<0.001^{*}$ \\
\hline Yes & $27(81.8 \%)$ & $10(15.6 \%)$ & & \\
\hline Eye rubbing on the steepest side & & & $21.7(6.68-66.4)$ & $<0.001^{*}$ \\
\hline Yes & $30(91 \%)$ & $7(10.9 \%)$ & & \\
\hline Eye rubbing with the dominant hand & & & $1.04(0.29-3.73)$ & 0.96 \\
\hline Yes & $29(87.9 \%)$ & $56(87.5 \%)$ & & \\
\hline Allergy & & & $2.94(1.15-7.48)$ & $0.02^{*}$ \\
\hline Yes & $25(75.8 \%)$ & $33(51.6 \%)$ & & \\
\hline Morning red eyes & & & $6.36(2.52-16.01)$ & $<0.001^{*}$ \\
\hline Yes & $23(69.7 \%)$ & $17(26.6 \%)$ & & \\
\hline Working at night & & & $0.87(0.24-2.88)$ & 0.87 \\
\hline Yes & $20(61 \%)$ & $38(59.4 \%)$ & & \\
\hline Computer Work & & & $0.88(0.34-2.30)$ & 0.81 \\
\hline Yes & $24(72.7 \%)$ & $48(75.0 \%)$ & & \\
\hline Stress at Work & & & $3.34(1.39-8.03)$ & 0.06 \\
\hline Yes & $21(63.6 \%)$ & $22(34.4 \%)$ & & \\
\hline Sleeping on stomach or sides & & & $14.31(4.78-42.84)$ & $<0.001^{*}$ \\
\hline Yes & $28(84.8 \%)$ & $18(28.1 \%)$ & & \\
\hline Sleeping on steepest side & & & $94.72(19.24-466.43)$ & $<0.001^{*}$ \\
\hline Yes & $31(93.9 \%)$ & $9(14.1 \%)$ & & \\
\hline
\end{tabular}

*Indicates a significant risk factor $(p<0.05)$

out of seven risk factors. Eye rubbing during the day (adjusted $\mathrm{OR}=134.96 ; p=0.002$, ) in the morning (adjusted OR = $24.86 ; p=0.014$ ), or in the steepest eye (adjusted $\mathrm{OR}=$ $27.56 ; p=0.002$ ) were significantly associated with the presence of UHAKC. Also, sleeping on stomach or sides (adjusted $\mathrm{OR}=65.02 ; p=0.001)$ or on the steepest side (adjusted $\mathrm{OR}=$ $144.01 ; p=0.001)$ were associated with the presence of UHAKC. In contrast, the association between the presence of an allergy and red eyes in the morning was not confirmed in the multivariate analysis when all predictors were included

Table 5 Multivariate analysis of risk factors for UHAKC

\begin{tabular}{lrll}
\hline Risk factor & Adjusted OR & 95\% CI & $p$ \\
\hline Eye rubbing during the day & 134.96 & {$[6.35-2868.17]$} & 0.002 \\
Eye rubbing in the morning & 24.86 & {$[2.13-288.93]$} & 0.014 \\
Eye rubbing in the steepest side & 27.56 & {$[3.25-207.88]$} & 0.002 \\
Sleeping on stomach or sides & 65.02 & {$[5.05-573.91]$} & 0.001 \\
Sleeping on steepest side & 144.01 & {$[7.37-2815.88]$} & 0.001 \\
\hline
\end{tabular}

*Indicates a significant risk factor $(p<0.05)$ in the model. The multivariate model containing these predictors was statistically significant $\left(n=97, \mathrm{df}=4, \chi^{2}=105.31\right.$, $p<0.001$ ), indicating that it was able to distinguish between UHAKC and control patients.

\section{Analysis of the UHAKC group}

Table 6 shows the corneal characteristics between the worse eye and the better eye in UHAKC patients, and the results of the univariate analysis of risk factors such as eye rubbing and sleeping position. Regarding topographic parameters, Kmax $(p=0.020), \mathrm{Kmin}(p=0.018)$, and Kmean $(p=0.036)$ were significantly higher in the worse eye than in the better eye. The CCT was significantly thinner in the worse eye than in the better eye, $495.73 \pm 31.07 \mu \mathrm{m}$ versus $509.14 \pm 36.08 \mu \mathrm{m}$ $(p<0.001)$, respectively. Similarly, the inferior-superior value (I-S) in the 3-mm area was significantly higher in the worse eye than in the better eye, $1.66 \pm 0.21$ versus $0.75 \pm 0.16$ $(p<0.001)$. The BCVA was also significantly lower in the worse eye $(0.66 \pm 0.22)$ than in the better eye $(0.97 \pm 0.10$; $p<0.001)$. All patients in this group had a preference for rubbing their worse eye, and $90.9 \%$ were used to sleeping 
Table 6 Comparisons between the worse and better eyes in the UHAKC group

\begin{tabular}{llll}
\hline & Worse eye & Better eye & Pearson chi-square $p$ value \\
\hline $\begin{array}{llll}\text { Parameters } \\
\text { Kmax (D) }\end{array}$ & $45.78 \pm 2.60$ & $44.99 \pm 1.82$ & 0.020 \\
Kmin (D) & $44.07 \pm 1.91$ & $43.11 \pm 1.71$ & 0.018 \\
Kmean (D) & $44.94 \pm 1.62$ & $43.62 \pm 1.65$ & 0.036 \\
CCT $(\mu \mathrm{m})$ & $495.73 \pm 31.07$ & $509.14 \pm 36.08$ & $<0.001$ \\
ISV $(3 \mathrm{~mm})$ & $1.66 \pm 0.21$ & $0.74 \pm 0.16$ & $<0.001$ \\
BCVA & $0.66( \pm 0.22)$ & $0.97( \pm 0.10)$ & $<0.001$ \\
Risk factors & & & \\
$\quad$ Eye rubbing in the same side & $33(100 \%)$ & $0(0 \%)$ & $p<0.001 ; 162.14[19.25-634.12]$ \\
$\quad$ Sleeping on the same side & $30(90.9 \%)$ & $3(9.1 \%)$ & $p<0.001 ; 99.74[19.87-508.21]$ \\
\hline
\end{tabular}

on the most affected side. A univariate analysis of eye rubbing and sleeping position was also performed to compare the worse eye and the better eye in the UHAKC group. Eye rubbing was 162.14-fold higher in the worse eye than in the better eye $(p<0.001)$. A higher number of patients were sleeping on the side of the worse eye than on the side of the better eye side $(\mathrm{OR}=99.74 ; p<0.001)$.

\section{Discussion}

This French case-control study aimed to identify new risk factors associated with UHAKC. The results showed a significant association between UHAKC and the following factors: eye rubbing, either during the day or in the morning and especially when it was done on the ipsilateral side; an incorrect sleeping position, i.e., sleeping on sides with the eye compressed against the pillow ("pillow hugging") or on their stomach. Also, eye rubbing and sleeping on the side of the worse eye were significantly higher than the better eye side in UHAKC patients. This study was the first methodical analysis of an incorrect sleeping position and eye rubbing habits in unilateral or highly asymmetric $\mathrm{KC}$. The results of this study regarding an association between eye rubbing and UHAKC were unequivocal. Our data also showed an association between an incorrect sleeping position and UHAKC, a finding that has never been described before in the literature, even if it had previously been suspected in patients with floppy eyelid syndrome [20, 31].

Eye rubbing has been shown to be associated with $\mathrm{KC}$, and this was confirmed in our multivariate analysis. Although atopy and eye rubbing have been previously investigated [10, $32,33]$, how eye rubbing is done and the sleeping position are new, especially in unilateral or highly asymmetrical $\mathrm{KC}$, and are related to the focal nature. However, the cause of keratoconus is still unknown [34], but rubbing the eye is a well-known risk factor [34, 35]. This supports the hypothesis of mechanical fatigue of the cornea after repeated shear stress on its surface, and it could be a possible mechanism for initiating and/or inducing progression of $\mathrm{KC}$, especially when the trauma is strong and prolonged. Korb et al. [36] have found that normal patients rubbed their eyes using their finger pads, generated a force $<0.45 \mathrm{~kg} / 2.54 \mathrm{~cm}^{2}$, whereas $\mathrm{KC}$ patients used their knuckles, rubbing longer and more often, and generated a force $>4.5 \mathrm{~kg} / 2.54 \mathrm{~cm}^{2}$. We agree that it is the more potent environmental factor for the development of $\mathrm{KC}$ [37]. In our study, all UHAKC patients were aware of the possible role of eye rubbing as a contributing factor in the development of $\mathrm{KC}$, and after receiving this information, they controlled the impulse to rub their eyes. Some studies have already shown the important role of eye rubbing [26, 27, 34-36, 38-41], especially during adolescence.

For example, Coyle and al. [38] have reported the occurrence of unilateral $\mathrm{KC}$ in a boy who used digital massage of the affected eye to control episodes of paroxysmal atrial tachycardia. Additionally, Lindsay et al. [39] have reported the case of a patient with unilateral punctal agenesis and epiphora who developed unilateral $\mathrm{KC}$ due to regular eye rubbing and tear wiping.

Regarding the sleeping position, we were the first to identify it as a risk factor for KC. Interestingly, the most affected eye did not correlate with the dominant hand, but rather with the preferential side on which patients were used to sleeping. In our study, UHAKC patients were used to sleeping more often on the side of the worse eye than on the side of the better eye. Keratoconus appears to be more common in patients who sleep on their stomach or on one side, which results in a compression of the globe and could be related to increased heat generated locally during sleep. There are several mechanisms $[40,41]$ by which eye rubbing and the sleeping position could be involved in $\mathrm{KC}$ development. It could be assumed that the release of interleukin-1 by a damaged corneal epithelium could result in keratocyte apoptosis and tissue remodeling [42]. A mechanical trauma and increased intraocular pressure could also contribute to the pathogenesis. According to us, the association of all these environmental factors, 
including eye rubbing, allergy, and an incorrect sleeping position (ocular compression and increased temperature), could lead to the known biochemical changes in $\mathrm{KC}$, i.e., increased activity of inflammatory mediators, induced keratocyte apoptosis, increased fibroblast activity, increased enzyme activities stretching the cornea (proteolytic enzymes) [43, 44], decreased proteinase inhibitor levels [45], and decreased stromal collagen. Thus, a vicious cycle could be induced because a biomechanical stress leads to biochemical changes and contributes to stromal thinning. Considering these arguments, we hypothesize that this focal biomechanical impairment could be primarily caused by eye rubbing, but probably with a stronger and prolonged impact of sleeping position in UHAKC eyes.

In our study, only one $\mathrm{KC}$ patient did not report any eye rubbing and no family history of $\mathrm{KC}$, which is related to the fact that most KC cases are sporadic. Furthermore, compared with other studies, the higher percentage of eye rubbing in our study could be explained by the repetition of the question during each consultation, sometimes with the help of a relative. In some cases, patients initially denied rubbing their eyes because they were not aware that they do it automatically, and the testimony of relatives helped patients to realize that they do in fact rub their eyes.

Though not specified in our results, our study also conclude that there is no significant association between smoking and $\mathrm{KC}$.

In addition to these considerations, patients with repeated episodes of allergy or dry eye could be at higher risk of keratoconus, again, due to excessive eye rubbing. Allergy has been found to be more prevalent in KC patients than in controls, as in the present study. The relationship between allergy and $\mathrm{KC}$ is less marked in our study than in other studies conducted in Israel [46], Lebanon [47], and Saudi Arabia [48]. This discrepancy may be due to the environmental influence of warm and sunny countries, which prevail in the abovementioned countries. This could explain the higher prevalence of $\mathrm{KC}$ reported in Middle East with an increased frequency of eye rubbing. We could consider the possibility that the direct and prolonged contact of the eyelids against the bed linen could increase the contamination of the ocular surface with irritants and allergens such as dust mites. This could contribute to increased local pruritus and subsequently to increased eye rubbing of the affected side, which could partly explain the asymmetry.

In our study, allergy was significantly associated with $\mathrm{KC}$ in the univariate analysis but not in the multivariate analysis. This could be due to the high prevalence of allergy in the control group (51.6\%), which could be in turn due to the small sample size in this cohort.

In addition, we decided to study whether stress at work and working in front of a computer screen had any effect. We assumed that these factors could be responsible for eye rubbing and therefore could have participated in the asymmetric nature of KC. In our study, these items were not significantly associated with $\mathrm{KC}$; again, this could be due to the small sample size and the high rates found in the control group. Thus, further studies are needed to confirm our findings.

Fortunately, not all eye rubbers or persons sleeping in an incorrect position will develop KC. Indeed, KC may well not develop before sustained and strong rubbing episodes after an extended period during which the cornea buckles permanently and induces irregular astigmatism and increased myopia via central or paracentral steepening. As already mentioned, we assumed that genetic factors for $\mathrm{KC}$ [49] could make the cornea more fragile and likely to develop $\mathrm{KC}$, but in the absence of repeated and vigorous corneal trauma, $\mathrm{KC}$ does not tend to manifest. Patients with diseases that reduce corneal resistance could also be more likely to experience progressive and permanent corneal deformation whilst applying a similar eye rubbing trauma.

This study has some limitations. Most data were selfreported by patients so that they might be subjected to a recall bias or omission, but since both $\mathrm{KC}$ and control patients were asked the same questions, the relative difference should prevail. However, the questions were very similar to those used in the questionnaire validated in other studies [26, 29]. Another limitation is the controversial definition of unilateral or highly asymmetrical KC. In 2015, the Global Consensus on Keratoconus and Ectatic Diseases brought together 4 multinational corneal societies (Cornea Society, Asia Cornea Society, PanCornea and EuCornea) to establish consensus statements and recommendations for the diagnostic and managements of keratoconus. One of the conclusions of the consensus was that "true unilateral keratoconus does not exist" but, "secondary unilateral induced ectasia may be caused by a pure mechanical process" [14]. Tomography $[29,50]$ is currently recognized as the best and most widely used test to diagnose early or subclinical $\mathrm{KC}$, and the use of quantitative videokeratographyderived indices $[51,52]$ could be more reproducible for quantifying unilateral or highly asymmetrical KC. Repetitive mechanical trauma [53] applied on the cornea results in a permanent thinning and deformation which also explains very well the frequent inter-eye asymmetry, as a large proportion of patients tend to rub one eye more than the other. We also evaluated the frequency of eye rubbing in the questionnaire, but we could not establish statistics on this item due to the variable and unreliable reports from patients. However, the importance of the frequency of eye rubbing is an important element in the development of keratoconus and tends to be associated with the severity and laterality of this disease. In some patients who rub only one eye, a strictly unilateral $\mathrm{KC}$ can be observed, and no clinically detectable topographic or biomechanical alteration can be found in the other unrubbed eye [54-56]. It should be noted that we monitored all patients 
of the UHAKC group for a minimum of 1 year, and none developed $\mathrm{KC}$ in the contralateral eye.

Furthermore, our relatively small sample size due to the low prevalence of unilateral KC and selective criteria used to define it limit the ability to discriminate with better precision, the risk among groups. A selection bias may have occurred in UHAKC patients because they were not aware that we compared them with non-UHAKC patients; the risk of systematic self-selection other than voluntary compliance is very limited. Therefore, cases and controls were individually matched only for age and sex, because it's known that $\mathrm{KC}$ is more prevalent in men than women, and appears in the second and third decade of life. We decided to select candidates for refractive surgery as controls because most of them were young, healthy, with sufficient myopia, and/or astigmatism to perform refractive surgery, allowing groups to be compared after matching on age and sex. Finally, it is noteworthy that the obtained results were only based on a single dataset, which need to be confirmed by other studies. Nevertheless, our data on the prevalence of the known risk factors were very similar to published data.

In summary, our data provide strong evidence of an association between eye rubbing, incorrect sleeping position, and UHAKC, emphasizing the need for public health awareness of the deleterious consequences of vigorous eye rubbing and incorrect sleeping position. Medical colleagues need to improve the management of eye rubbing and to detect an incorrect sleeping position in diagnosed $\mathrm{KC}$ or patients at risk. Further studies are needed to evaluate the long-term stability of $\mathrm{KC}$ after eye rubbing cessation and adopting a new correct sleeping position.

Acknowledgments We would like to thank Sophie Pegorier for her critical review of the manuscript.

Availability of data and material Available on request. Code availability Not Applicable.

\section{Compliance with ethical standards}

Conflict of interest All authors certify that they have no affiliations with or involvement in any organization or entity with any financial interest (such as honoraria; educational grants; participation in speakers' bureaus; membership, employment, consultancies, stock ownership, or other equity interest; and expert testimony or patent-licensing arrangements), or non-financial interest (such as personal or professional relationships, affiliations, knowledge or beliefs) in the subject matter or materials discussed in this manuscript. No Potential conflict of interest relevant to this article.

Ethical approval All procedures performed in studies involving human participants were in accordance with the ethical standards of the Rothschild Foundation (Paris) research committee and with the 1964 Helsinki declaration and its later amendments or comparable ethical standards.
Informed consent Informed consent was obtained from all individual participants included in the study.

Open Access This article is licensed under a Creative Commons Attribution 4.0 International License, which permits use, sharing, adaptation, distribution and reproduction in any medium or format, as long as you give appropriate credit to the original author(s) and the source, provide a link to the Creative Commons licence, and indicate if changes were made. The images or other third party material in this article are included in the article's Creative Commons licence, unless indicated otherwise in a credit line to the material. If material is not included in the article's Creative Commons licence and your intended use is not permitted by statutory regulation or exceeds the permitted use, you will need to obtain permission directly from the copyright holder. To view a copy of this licence, visit http://creativecommons.org/licenses/by/4.0/.

\section{References}

1. Gordon-Shaag A, Millodot M, Shneor E (2012) The epidemiology and etiology of keratoconus. Int J Keratoconus Ectatic Corneal Dis 1(1):7-15

2. Holland DR, Maeda N, Hannush SB et al (1997) Unilateral keratoconus. Incidence and quantitative topographic analysis. Ophthalmology 104:1409-1413

3. Kennedy RH, Bourne WM, Dyer JA (1986) A 48-year clinical and epidemiological study of keratoconus. Am J Ophthalmol 101:267273

4. Gordon-Shaag A, Millodot M, Essa M et al (2013) Is consanguinity a risk factor for keratoconus? Optom Vis Sci 90:448-454

5. Edwards M, McGhee CN, Dean S (2001) The genetics of keratoconus. Clin Exp Ophthalmol 6:345-351

6. Wang Y, Rabinowitz YS, Rotter JI et al (2000) Genetic epidemiological study of keratoconus: evidence for major gene determination. Am J Med Genet 93:403-409

7. Rahi A, Davies P, Ruben M et al (1977) Keratoconus and coexisting atopic disease. Br J Ophthalmol 61:761-764

8. Rabinowitz YS (1998) Keratoconus. Surv Ophthalmol 42:297-319

9. Naderan M, Shoar S, Rezagholizadeh F et al (2015) Characteristics and associations of keratoconus patients. Cont Lens Anterior Eye 38:199-205

10. Bawazeer A, Hodge W, Lorimer B (2000) Atopy and keratoconus: a multivariate analysis. Br J Ophthalmol 84:834-836

11. Kaldawy RM, Wagner J, Ching S et al (2002) Evidence of apoptotic cell death in keratoconus. Cornea. 2:206-209

12. McMonnies CW, Boneham GC (2003) Keratoconus, allergy, itch, eye rubbing and hand-dominance. Clin Exp Optom 86:376-384

13. Bral N, Termote K (2017) Unilateral keratoconus after chronic eye rubbing by the nondominant hand. Case Rep Ophthalmol 8:558 561

14. Gomes JAP, Tan D, Rapuano CJ et al (2015) Global consensus on keratoconus and ectatic diseases. Cornea. 34:359-369

15. Saidel MA, Paik JY, Garcia C et al (2012) Prevalence of sleep apnea syndrome and high-risk characteristics among keratoconus patients. Cornea. 31:600

16. Pedrotti E, Demasi CL, Fasolo A et al (2018) Obstructive sleep apnea assessed by overnight polysomnography in patients with keratoconus. Cornea. 37(4):470-473

17. West SD, Turnbull C (2016) Eye disorders associated with obstructive sleep apnoea. Curr Opin Pulm Med 22(6):595-601

18. Naderan M, Rezagholizadeh F, Zolfaghari M et al (2015) Association between the prevalence of obstructive sleep apnoea and the severity of keratoconus. Br J Ophthalmol 99(12):16751679 
19. Gupta PK, Stinnett SS, Carlson AN (2012) Prevalence of sleep apnea in patients with keratoconus. Cornea. 31(6):595-599

20. Pihlblad MS, Schaefer DP (2013) Eyelid laxity, obesity, and obstructive sleep apnea in keratoconus. Cornea. 32(9):1232-1236

21. Kymionis GD, Grentzelos MA, Liakopoulos DA et al (2014) Corneal collagen crosslinking failure in a patient with floppy eyelid syndrome. J Cataract Refract Surg 40(9):1558-1560

22. Correia FF, Ramos I, Lopes B et al (2012) Topometric and tomographic indices for the diagnosis of keratoconus. Int J Keratoconus Ectatic Corneal Dis. 1:92-99

23. Saad A, Gatinel D (2016) Combining placido and corneal wavefront data for the detection of forme fruste keratoconus. J Refract Surg 32(8):510-516

24. Belin MW, Villavicencio OF, Ambrosio R Jr (2014) Tomographic parameters for the detection of keratoconus: suggestions for screening and treatment parameters. Eye Contact Lens 40:326-330

25. Imbornoni LM, Padmanabhan P, Belin MW et al (2017) Long-term tomographic evaluation of unilateral keratoconus. Cornea. 36(11): $1316-1324$

26. Gordon-Shaag A, Millodot M, Kaiserman I et al (2015) Risk factors for keratoconus in Israel: a case-control study. Ophthalmic Physiol Opt 35(6):673-681

27. Mashor RS, Kumar NL, Ritenour RJ et al (2011) Keratoconus caused by eye rubbing in patients with Tourette syndrome. Can $\mathrm{J}$ Ophthalmol 46:83-86

28. Weed KH, MacEwen CJ, Giles T et al (2008) The Dundee University Scottish Keratoconus study: demographics, corneal signs, associated diseases, and eye rubbing. Eye (Lond). 22:534 541

29. Owens H, Gamble G (2003) A profile of keratoconus in New Zealand. Cornea 22:122-125

30. Gatinel D, Mazharian A, Chan C et al (2015) Cases in the keratoconus diary [the keratoconus diary web site ]. October 12 . Available at: https://defeatkeratoconus.com/allcases/. Accessed May 10, 2020

31. Ezra DG, Beaconsfield M, Sira M et al (2010) The associations of floppy eyelid syndrome: a case control study. Ophthalmology. 117: 831-838

32. Ebihara N, Funaki T, Matsuda $\mathrm{H}$ et al (2008) Corneal abnormalities in the NC/Nga mouse. An atopic dermatitis model. Cornea 27:923992

33. Moran S, Gomez L, Zuber K, Gatinel D (2020) A case-control study of keratoconus risk factors. Cornea 39(6):697-701

34. Davidson AE, Hayes S, Hardcastle AJ et al (2014) The pathogenesis of keratoconus. Eye (Lond) 28:189-195

35. Krachmer JH (2004) Eye rubbing can cause keratoconus. Cornea 6: 539-540

36. Korb DR, Leahy CD, Greiner JV (1991) Prevalence and characteristics of eye-rubbing for keratoconic and non-keratoconic subjects. Invest Ophthalmol Vis Sci 32:1057

37. Gatinel D (2016) Eye rubbing, a sine qua non for keratoconus? Int J Keratoconus Ectatic Corneal Dis 5:6-12

38. Coyle JT (1984) Keratoconus and eye rubbing. Am J Ophthalmol 97:527-528
39. Lindsay RG, Bruce AS, Gutteridge IF (2000) Keratoconus associated with continual eye rubbing due to punctal agenesis. Cornea 19: 567-569

40. McMonnies CW (2009) Mechanisms of rubbing-related corneal trauma in keratoconus. Cornea 28:607-615

41. Norouzpour A, Mehdizadeh A (2012) A novel insight into keratoconus: mechanical fatigue of the cornea. Med Hypothesis Discov Innov Ophthalmol 1:14-17

42. Wilson SE, He YG, Weng J et al (1996) Epithelial injury induces keratocyte apoptosis: hypothesized role for the interleukin-1 (IL-1) system in the modulation of corneal tissue organization. Exp Eye Res 62:325-338

43. Collier SA (2001) Is the corneal degradation in keratoconus caused by matrix metalloproteinases? Clin Exp Ophthalmol 29:340-344

44. Mackiewicz Z, Maatta M, Stenman M et al (2006) Collagenolytic proteinases in keratoconus. Cornea 25:603-610

45. Matthews FJ, Cook SD, Majid MA et al (2007) Changes in the balance of the tissue inhibitor of matrix metalloproteinases (TIMPs)-1 and -3 may promote keratocyte apoptosis in keratoconus. Exp Eye Res 84:1125-1134

46. Shneor E, Millodot M, Gordon-Shaag A et al (2014) Prevalence of keratoconus among young Arabs students in Israel. Int J Keratoconus Ectatic Corneal Dis 3:9-14

47. Waked N, Fayad AM, Fadlallah A et al (2012) Keratoconus screening in a Lebanese students' population. J Fr Ophtalmol 35:23-29

48. Assiri AA, Yousuf BI, Quantock AJ et al (2005) Incidence and severity of keratoconus in Asir province. Saudi Arabia Br J Ophthalmol 89:1403-1406

49. Rabinowitz YS (2003) The genetics of keratoconus. Ophthalmol Clin North Am 16:607Y20

50. Lee LR, Hirst LW, Readshaw G (1995) Clinical detection of unilateral keratoconus. Aust N Z J Ophthalmol 23:129-133

51. Ambrosio R, Caiado AL, Guerra FP et al (2011) Novel pachymetric parameters based on corneal tomography for diagnosing keratoconus. J Refract Surg 27:753-758

52. Kanellopoulos AJ, Asimellis G (2013) Keratoconus diagnosis and progression classification based on evaluation of corneal asymmetry indices, derived from Scheimpflug imaging in keratoconic and suspect cases. Clin Ophthalmol 7:1539-1548

53. Gritz DC, McDonnell PJ (1988) Keratoconus and ocular massage. Am J Ophthalmol 106:757-758

54. Fakhraie G, Vahedian Z (2016) Post filtering surgery globe massage-induced keratoconus in an eye with iridocorneal endothelial syndrome: a case report and literature brief review. J Ophthalmic Vis Res 11:319-322

55. Ioannidis AS, Speedwell L, Nischal KK (2005) Unilateral keratoconus in a child with chronic and persistent eye rubbing. Am J Ophthalmol 139:356-357

56. Jafri B, Lichter H, Stulting RD (2004) Asymmetric keratoconus attributed to eye rubbing. Cornea 23:560-564

Publisher's note Springer Nature remains neutral with regard to jurisdictional claims in published maps and institutional affiliations. 